\title{
EFFECT OF FILLER NATURE AND CONTENT ON THE BITUMINOUS MASTIC BEHAVIOUR UNDER CYCLIC LOADS
}

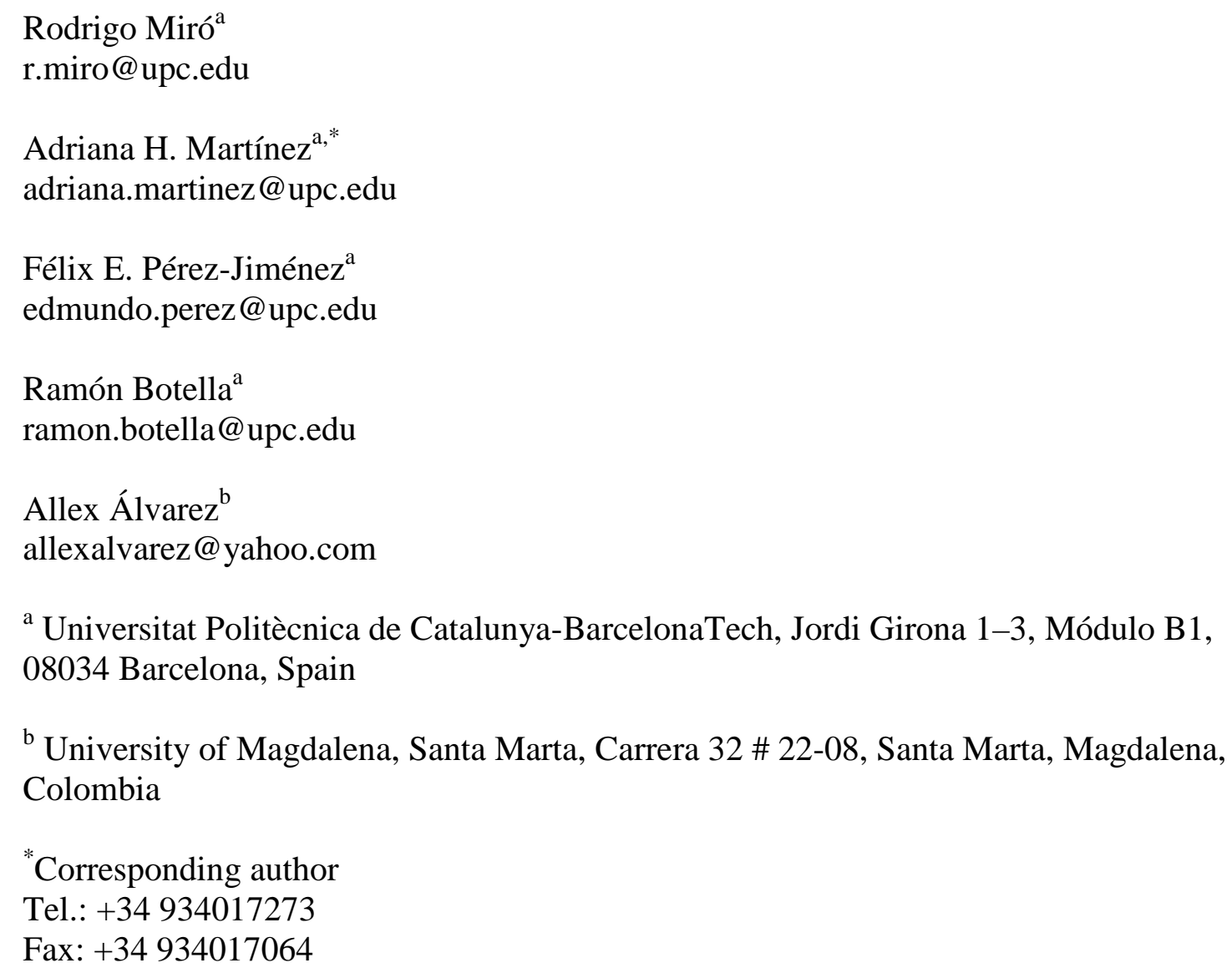

\section{Abstract}

The role of the filler in asphalt mixtures is particularly important because of its influence on mastic behaviour. The filler improves the resistance properties of bitumen against the action of traffic loads and temperature. However, the filler can also adversely affect bitumen in mastics excessively brittle and stiff due to inappropriate design. For these reasons, it is interesting to investigate the effect of filler type and content on mastic composition. This paper presents results from a strain sweep test applied to bituminous mastics prepared with different filler types and contents at several temperatures. The obtained stiffness modulus and failure strain results provide information to assess the fatigue behaviour of the analysed mastics.

Keywords: Filler, Hydrated lime, Limestone, Granite, Volumetric concentration, Strain sweep test

\section{Introduction}

Bituminous mastic obtained by mixing a filler with a bituminous binder greatly affects the behaviour of the bituminous mixture. It is known that the addition of filler increases the viscosity, stiffness and tensile strength of bitumen, leading to improved mixture cohesion and reduced thermal susceptibility [1]. 
The most extensively studied physico-chemical variables of fillers related to mastic behaviour are shape, size, nature and content [2-7]. Regarding the degree of packing of filler particles, significant differences exist between natural fillers. Moreover, the degree of packing has been found to affect both mastic and mixture behaviour, although no correlation has been observed between test results of mastics and mixtures due to complex interactions between the components of the mixture [8].

Some researchers have designed equipment to study the effect of filler particle size on the viscoelastic properties of mastic. For example, Delaporte et al. [9, 10] developed an annular shear rheometer and concluded that the use of ultrafine particles increases the complex modulus of mastic at high temperature, compared to mastic prepared with conventional fillers.

Clopotel et al proposed a novel method to estimate the change in viscosity of binders due to the addition of fillers using glass transition temperature measurements [11]. Hesami et al. [12, 13] developed an empirical framework for determining mastic viscosity as a function of filler concentration, demonstrating once again the complexity of studying the behaviour of bituminous mastics.

It is equally important to highlight the adverse effects of high filler contents in mastic, such as decrease in ductility, as too much filler can lead to fragile and brittle mastic. Furthermore, the filler can sometimes have a hydrophilic character, i.e. a greater ability to combine with water than with bituminous binder. This can result in a stripping process of the mixture in the presence of water, resulting in loss of cohesion and strength.

Therefore, the composition of the mastic should be carefully studied to select the appropriate filler type and content to be incorporated in order to achieve the desired physico-mechanical and volumetric properties. Former investigations by Rigden [14] and Ruiz [15, 16] propose to limit filler addition to avoid an excessive volumetric concentration in the filler-bitumen system; this "overfillerization" would lead to high stiffness and the resulting loss of resistance to deformation, especially at low temperatures.

Buttlar et al. [17] conducted an experimental program to predict the properties of mastic in a wide range of temperatures and with different filler contents. They found that particle-interaction reinforcement may play a minor role at low filler concentrations whereas this mechanism is significant at high filler contents. They also concluded that hydrated lime provided a much higher level of physicochemical reinforcement than baghouse fillers.

A recent study on Test Methods and Specification Criteria for Mineral Filler Used in HMA [18] conducted at the University of Wisconsin-Madison developed and set some models to define indicators of workability, resistance to plastic deformation and stiffness at low temperatures. Faheem et al. proposed a model for predicting the complex modulus of the mastic as a function of the filler and bitumen properties [19]. Shen et al. [20] verified the application of the Ratio of Dissipated Energy Change (RDEC) approach to evaluate the fatigue properties of viscoelastic materials, (bituminous mixtures, mastics and binders), and found a unique relationship between the parameter determined with this RDEC concept and the corresponding fatigue life, 
independent of the material type and loading mode. Yin et al. [21] carried out a research to assess the micromechanical models developed to predict complex modulus and analyse the simplifications and limitations assumed in each model. They found that the simplifications of some models affected the accuracy of the predictions, underestimating some of the mastic properties or overestimating the experimental results.

The present study aims to analyse the effect of filler type and content on the fatigue behaviour of mastics at different temperatures by a strain sweep test (EBADE test, in Spanish Ensayo de BArrido de DEformaciones, which stands for "strain sweep test") [22], developed at the Road Research Laboratory of the Universitat Politècnica de Catalunya.

\section{Materials}

Three different mastics were prepared with 50/70 penetration grade bitumen and three types of fillers: two natural types, a granite filler and a limestone filler, and a hydrated lime filler. The mineralogical composition of the filler is the cause of the mechanical bonding achieved by the filler-bitumen system, in addition to increasing the viscosity of the bituminous mastic [23].

Mineral dust was added in volumetric concentrations. To this aim, the maximum volume of filler which can be added to thicken the binder film was determined by a sedimentation test to ensure that the binder film coats every filler particle. A viscous hydrocarbon fluid with lower viscosity than bitumen, such as kerosene, can be used to facilitate settlement.

The critical concentration determined by the sedimentation test corresponds to a dispersion of filler particles in the bitumen moving as freely as possible but in contact with each other, that is, when applied stresses in the viscous deformation of the continuous filler-bitumen medium are such that frictional resistance between particles is at a minimum.

Such a particle arrangement is expected in the sediment obtained by simple settling of filler dispersion in a fluid medium chemically related to bitumens, like kerosene. Ruiz [16] proposes a simple sedimentation test to find the critical value which guarantees mastic viscous behaviour. This test is known as "Sediment concentration", or most commonly, "Critical concentration”, [24]. Bressi et al. used an equation to determine critical filler concentration based on Rigden voids and methylene blue value [25].

In this study, critical concentration is calculated with the following equation:

$$
C_{s}=\frac{V_{f i l l e r}}{V_{s}}=\frac{P_{f} / \gamma_{f}}{V_{s}}
$$

where

$C_{s}$ : critical concentration of filler

$V_{\text {filler }}$ : volume of filler $\left(\mathrm{cm}^{3}\right)$

$P_{f}$ : mass of filler (g)

$V_{s}$ : settled volume of filler in anhydrous kerosene after 24 hours $\left(\mathrm{cm}^{3}\right)$ 
$\gamma_{f}$ : density of filler $\left(\mathrm{g} / \mathrm{cm}^{3}\right)$

When filler is added to mixtures, bituminous mastic viscosity increases gradually with increasing the volumetric concentration $(\mathrm{Cv})$. In the case of asphalt bitumens, when $\mathrm{Cv}$ $>C$ s, the biphasic system stops being viscous and an internal structure determining a net non-Newtonian flow appears, which renders the mix stiff.

Different volumetric concentrations divided by the critical concentration (Cv/Cs) were used for each filler, with $\mathrm{Cv}$ being determined by the following equation:

$$
C_{V}=\frac{V_{\text {filler }}}{V_{\text {filler }}+V_{\text {bitumen }}}=\frac{P_{f} / \gamma_{f}}{P_{f} / \gamma_{f}+P_{b} / \gamma_{b}}
$$

where

$C_{V}$ : volumetric concentration of filler

$V_{\text {filler }}$ and $V_{\text {bitumen }}$ : volume of filler and volume of bitumen $\left(\mathrm{cm}^{3}\right)$, respectively

$P_{f}$ and $P_{b}$ : mass of filler and mass of bitumen (g), respectively

$\gamma_{f}$ and $\gamma_{b}$ : density of filler and of bitumen $\left(\mathrm{g} / \mathrm{cm}^{3}\right)$, respectively

The $\mathrm{Cv} / \mathrm{Cs}$ concentrations used in this study are 0 (neat bitumen), 0.5, 1.0 and 1.25. Table 1 shows the characteristics of the bitumens and table 2 shows the density of the fillers, as well as the critical concentration, and the volumetric and mass concentrations.

Table 1. Characteristics of bitumens (Source: REPSOL)

\begin{tabular}{l|c|c|c}
\hline Characteristics & Unit & Standard & B50/70 \\
\hline \multicolumn{3}{c|}{ Original Bitumen } \\
\hline Penetration at $25^{\circ} \mathrm{C}$ & $(0.1 \mathrm{~mm})$ & EN 1426 & 59 \\
\hline Softening Point R\&B & $\left({ }^{\circ} \mathrm{C}\right)$ & EN 1427 & 50.2 \\
\hline Fraass Brittle Point & $\left({ }^{\circ} \mathrm{C}\right)$ & EN 12593 & -11 \\
\hline \multicolumn{3}{c}{ After RTFOT } \\
\hline Mass Loss & $(\%)$ & EN 12607-1 & 0.02 \\
\hline Retained Penetration at $25^{\circ} \mathrm{C}$ & $(\%)$ & EN 1426 & 62 \\
\hline Increase in Softening Point & $\left({ }^{\circ} \mathrm{C}\right)$ & EN 1427 & 7.0 \\
\hline
\end{tabular}

Table 2. Characteristics of fillers

\begin{tabular}{|c|c|c|c|c|}
\hline Filler Type & Density & Cs & Cv/Cs Ratio & f/b Ratio \\
\hline \multirow{3}{*}{ Granite } & \multirow{3}{*}{2.662} & \multirow{3}{*}{0.330} & 0.5 & 0.51 \\
\hline & & & 1 & 1.27 \\
\hline & & & 1.25 & 1.82 \\
\hline \multirow{3}{*}{ Limestone } & \multirow{3}{*}{2.683} & \multirow{3}{*}{0.277} & 0.5 & 0.42 \\
\hline & & & 1 & 1 \\
\hline & & & 1.25 & 1.38 \\
\hline \multirow{3}{*}{ Lime } & \multirow{3}{*}{2.375} & \multirow{3}{*}{0.121} & 0.5 & 0.15 \\
\hline & & & 1 & 0.32 \\
\hline & & & 1.25 & 0.41 \\
\hline
\end{tabular}



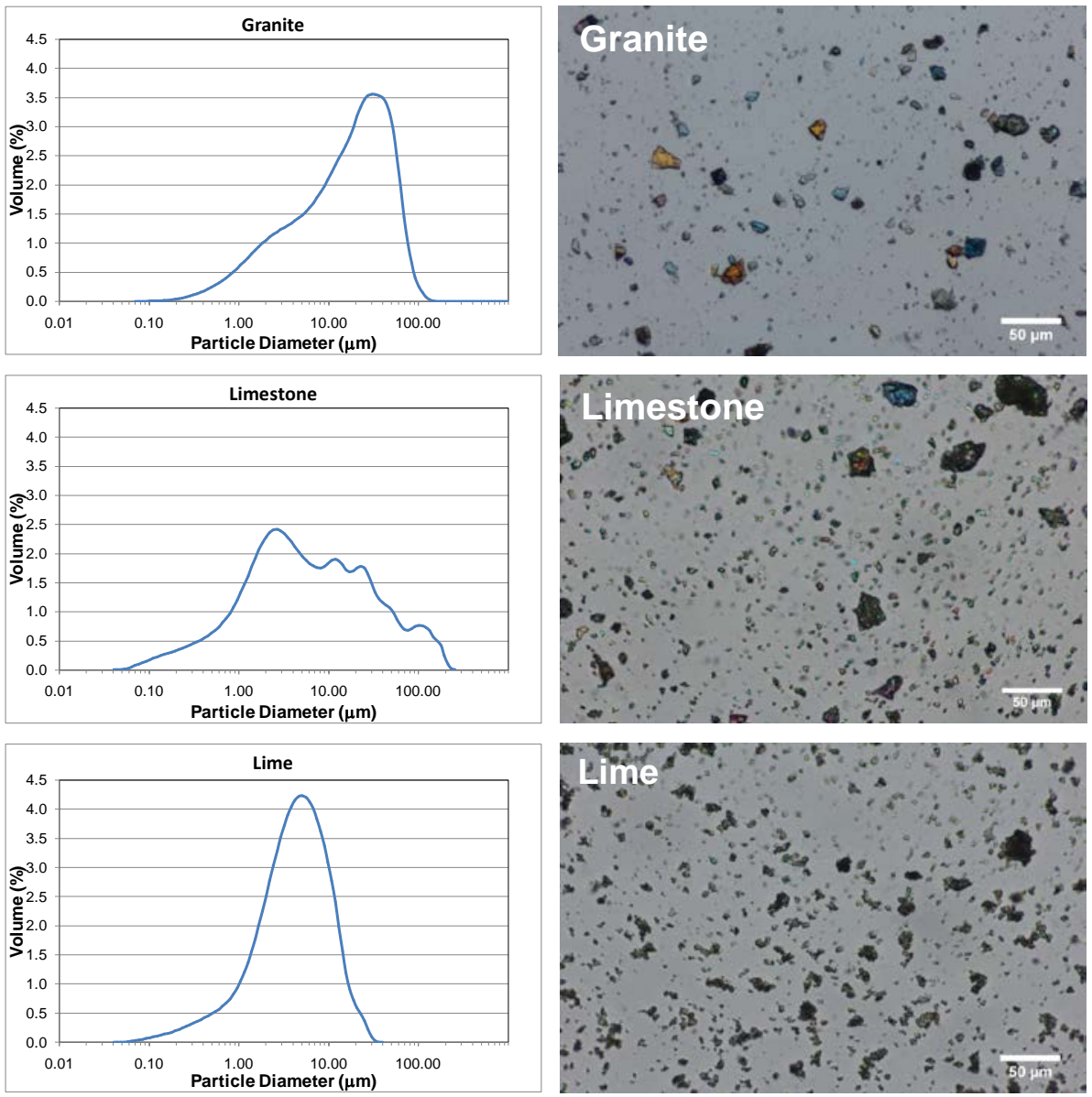

Figure 1. Filler particle shape and distribution

Particle size and shape affect the mechanical properties of mastics, such as stiffness, toughness, fracture energy, as stated by Antunes et al. and Movilla-Quesada et al. [2629]. Figure 1 shows the particle size distribution of each filler, obtained with a Laser Diffraction Particle Size Analyser, together with an image of the particle shape and distribution, obtained with an optical microscope. The photographs indicate that the shapes of the largest granite particles are clearly different from those of the other fillers. It can also be seen that the limestone particle size is quite large (some of the particles are larger than $63 \mu \mathrm{m}$ ) and lime particles tend to lump despite the fact that the lime filler is the most homogeneous in terms of particle size distribution.

\section{Testing method}

All the specimens of mastic were fabricated with the aforementioned bitumen and fillers, mixing both materials uniformly before proceeding to the specimen moulding. The mastic specimens were cylinders of $20 \mathrm{~mm}$ of diameter and around $40 \mathrm{~mm}$ in height, Figure 2a. The type of the specimen is similar to that used by Molenaar et al. although the dimensions are greater [30]. The asphalt binder was heated to $145-155^{\circ} \mathrm{C}$ in the oven, except when granite filler was used at the higher volumetric concentration, for which it was necessary to increase the temperature by $30^{\circ} \mathrm{C}$ due to its high viscosity. Mastic mixtures were poured into the cylindrical moulds at $135-145^{\circ} \mathrm{C}$, and after that the moulds were vibrated for 30 seconds. Specimens were left to cool at room temperature; after removing the specimens from the mould they were glued to a servohydraulic press in order to perform the tests, Figure $2 b$. 
206

207

208

209

210

211

212

213

214

215

216

217

218

219

220
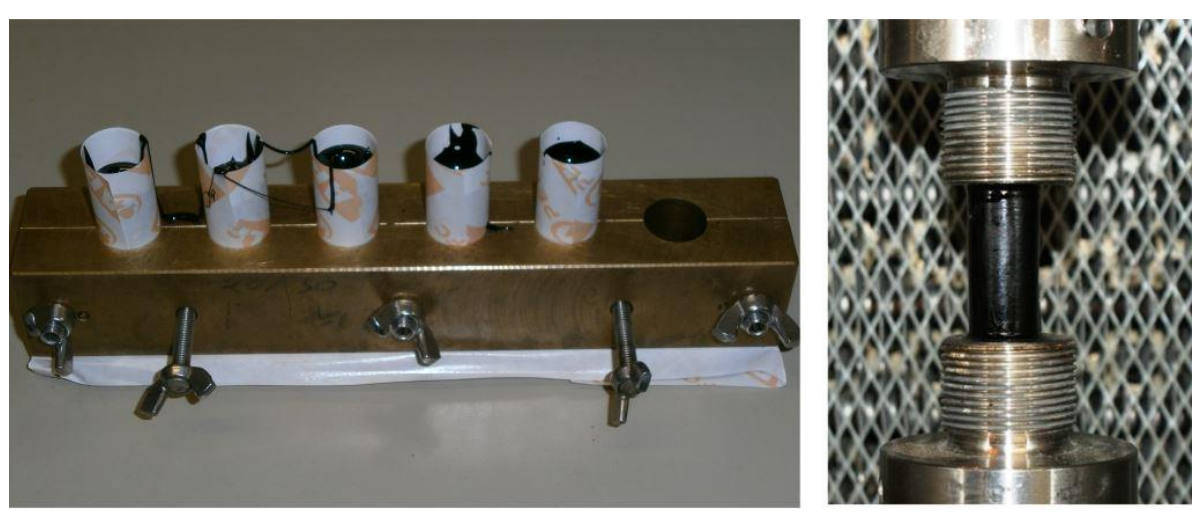

Figure 2. (a) Preparation of mastic specimens and (b) EBADE test set up

EBADE test is a cyclic tension-compression test at controlled strain. Several strain amplitudes in ascending order in stages of 5,000 loading cycles at a frequency of $10 \mathrm{~Hz}$ are applied.

The strain amplitude applied in the first step is 7.6E-4, and every 5,000 cycles the strain increases in 7.6E-4. This way the number of cycles and the strain amplitude are directly related. The test finishes when the total failure of the specimen takes place.

Images taken during the performance of the test until failure of the specimen are presented in Figure 3 as well as the appearance of the sample after having been tested.
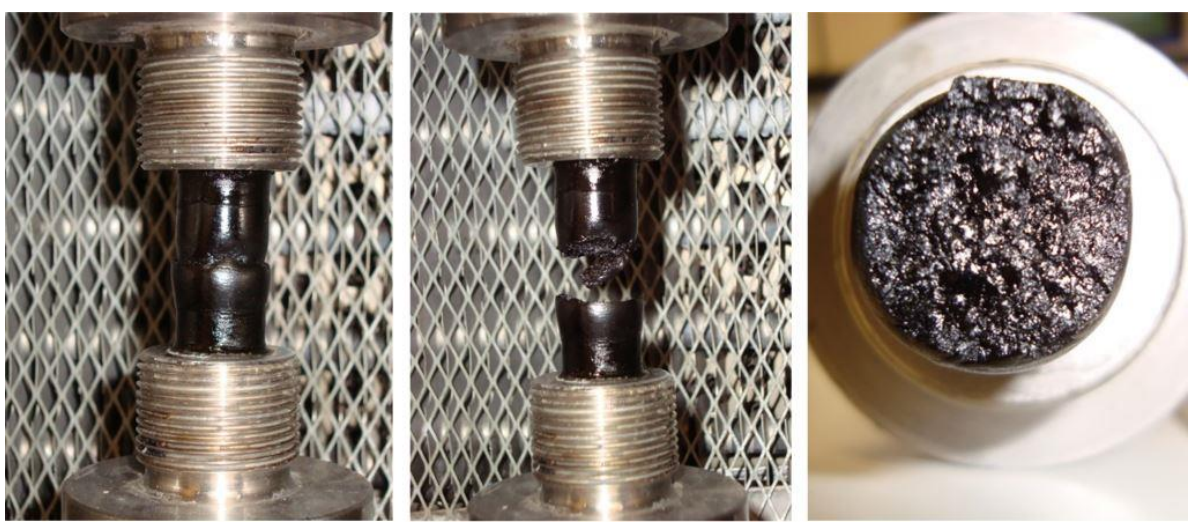

Figure 3. EBADE test in mastics: (a) initial strain, (b) specimen failure, (c) specimen appearance after failure

Several parameters can be computed during the test. The most important are maximum stress, complex modulus and dissipated energy density, during each cycle. Stress can be determined from equation (3):

$\sigma=\frac{F}{S}$

where $\sigma(\mathrm{MPa})$ is the stress, $F(\mathrm{~N})$ is the applied load and $S\left(\mathrm{~mm}^{2}\right)$ is the specimen cross section.

Using the maximum stress and strain it is possible to obtain the complex modulus by

means of equation (4): 
where $\left|E^{*}\right|(\mathrm{MPa})$ is the complex modulus, $\sigma_{\max }(\mathrm{MPa})$ is the maximum stress amplitude registered in a cycle and $\varepsilon_{\max }$ is strain amplitude imposed.

The initial modulus given by the test is obtained as the average of the moduli registered in all cycles corresponding to the first strain step (amplitude of $7.6 \mathrm{E}-4$ ). At these low strain levels the behaviour of the material is linear.

Due to the delay between stress and strain an ellipse is formed in the stress vs. strain plot. The dissipated energy density is proportional to the area of the ellipse in the tensioncompression graph. To compute this area from the test data, the Gauss Determinant Formula was used in the following equation:

$D E D=\frac{1}{2}\left[\left(\sigma_{1} \varepsilon_{2}+\sigma_{2} \varepsilon_{3}+\ldots+\sigma_{n-1} \varepsilon_{n}+\sigma_{n} \varepsilon_{1}\right)-\left(\sigma_{2} \varepsilon_{1}+\sigma_{3} \varepsilon_{2}+\ldots+\sigma_{n} \varepsilon_{n-1}+\sigma_{1} \varepsilon_{n}\right)\right] 10^{6}$

where $D E D\left(\mathrm{~J} / \mathrm{m}^{3}\right)$ is Dissipated Energy Density and $\sigma_{i}(\mathrm{MPa})$ and $\varepsilon_{i}$ are the $\mathrm{n}$ values of stress and strain obtained during a cycle.

Given the characteristics of the test, it is possible to obtain the strain at which the material is completely broken, failure strain. Specifically, the typical shape of the curves of dissipated energy density versus number of cycles allows easily determining the value of the failure strain. The reason is that DED increases throughout the test with the number of cycles to a maximum, after which it starts to decrease rather quickly as a result of the specimen failure. Consequently, a new parameter called failure strain is defined as the strain at which the dissipated energy density is reduced by $50 \%$ of the maximum value reached during the test, Figure 4.

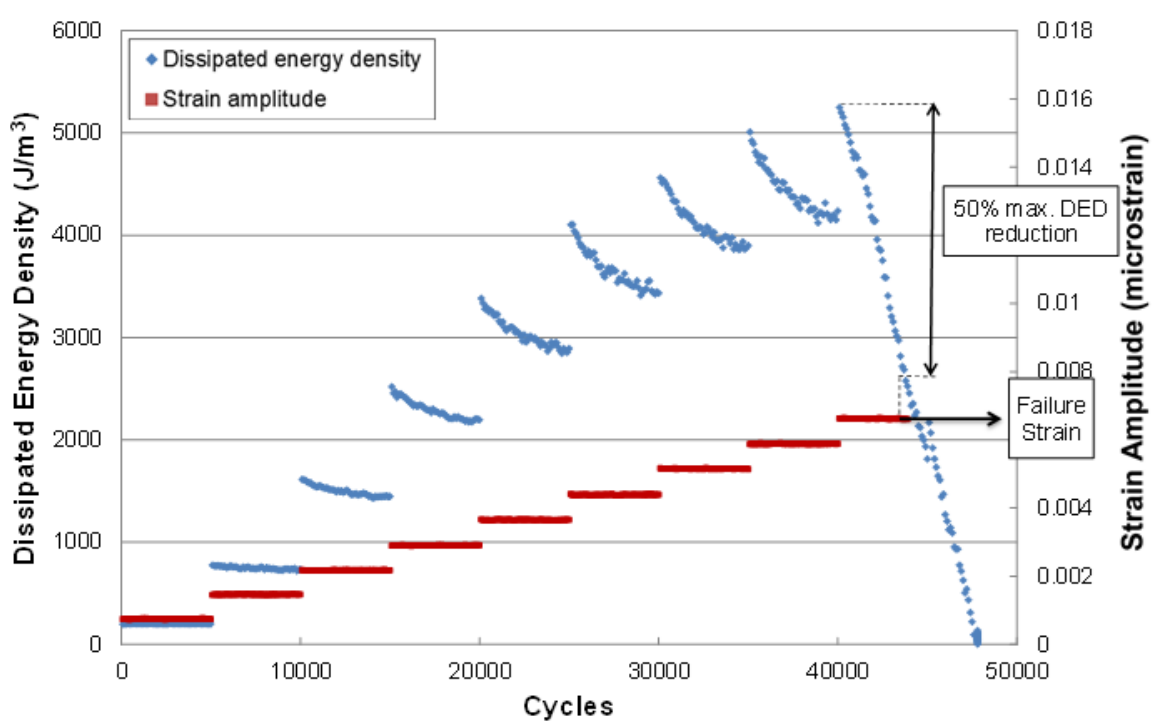

Figure 4. Failure criterion. Obtainment of failure strain

In this case, the test was performed at three different temperatures, 20,10 and $0^{\circ} \mathrm{C}$, in order to evaluate the behaviour of different mastics under different conditions. At low 
temperatures, mastics can show a more fragile response than at room temperature and therefore, be more critical for the fatigue resistance. It is interesting to note that EBADE test was used previously to analyze the fatigue response of different types of bitumen (penetration, polymer modified and crumb rubber modified bitumens) at different temperatures and the results obtained confirmed their agreement with those from DSR,

\section{Analysis of results}

As an example, figures 5 and 6 show the variation in stiffness modulus and dissipated energy density with the number of cycles at $10^{\circ} \mathrm{C}$ for mastics obtained with the limestone filler at different volumetric concentrations. It is clearly observed how modulus at the first cycle and dissipated energy density increase with the increase in volumetric concentration whereas the failure cycle gradually decreases.

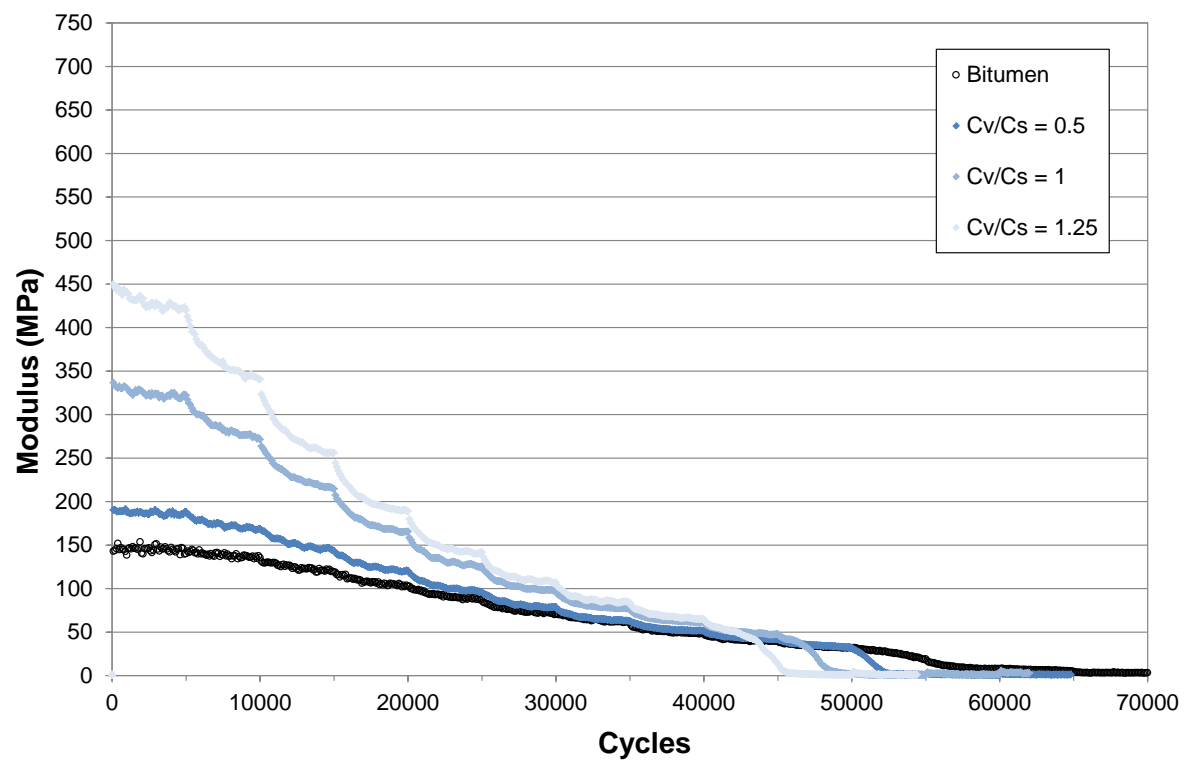

Figure 5. Stiffness modulus versus number of cycles at $10^{\circ} \mathrm{C}$. Limestone filler 


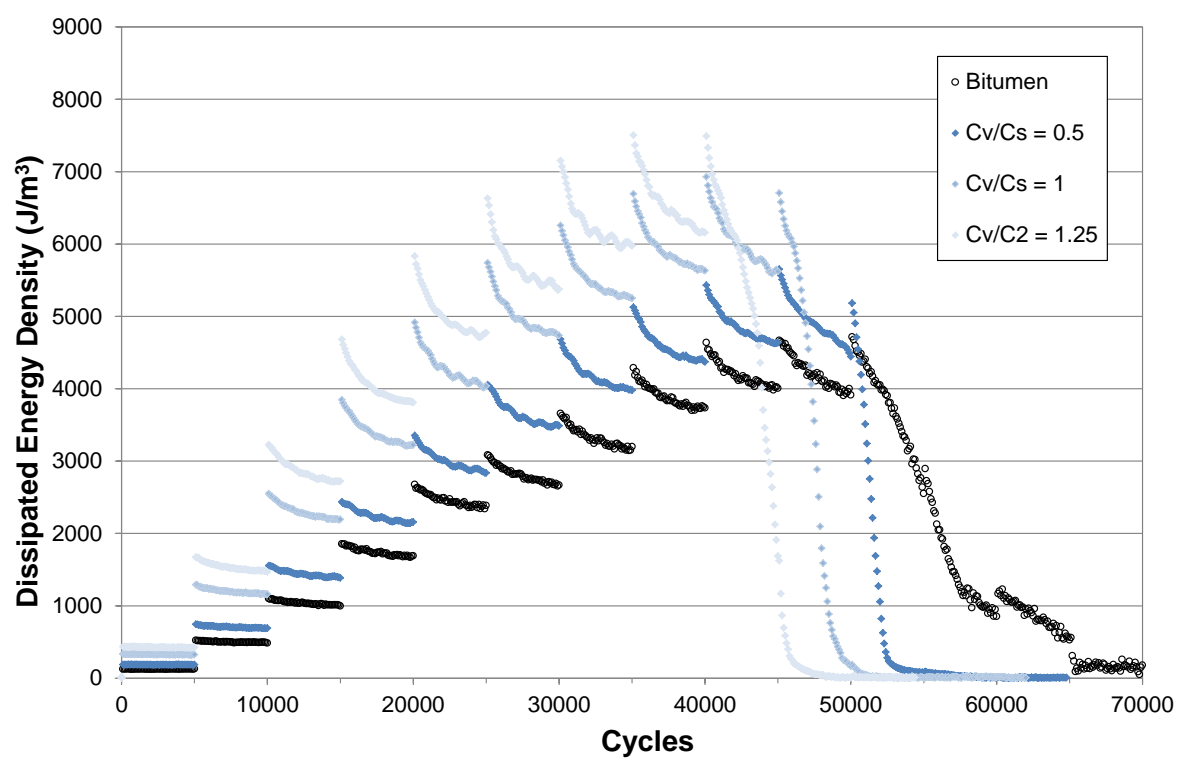

291

Figure 6. Dissipated energy density versus number of cycles at $10^{\circ} \mathrm{C}$. Limestone filler

Table 3 summarizes the mean values of the parameters obtained from EBADE test at the three test temperatures for each mastic analysed.

Table 3. Results of EBADE test

\begin{tabular}{|c|c|c|c|c|c|c|c|c|}
\hline \multirow[t]{2}{*}{ Filler } & \multirow[t]{2}{*}{$\mathrm{Cv} / \mathrm{Cs}$} & \multirow[t]{2}{*}{$\mathbf{f} / \mathbf{b}$} & \multicolumn{3}{|c|}{$\begin{array}{l}\text { Initial Modulus } \\
\text { (MPa) }\end{array}$} & \multicolumn{3}{|c|}{$\begin{array}{c}\text { Failure Strain } \\
\text { ( } \mu \text { def) }\end{array}$} \\
\hline & & & $20^{\circ} \mathrm{C}$ & $10^{\circ} \mathrm{C}$ & $0^{\circ} \mathrm{C}$ & $20^{\circ} \mathrm{C}$ & $10^{\circ} \mathrm{C}$ & $0^{\circ} \mathrm{C}$ \\
\hline Without Filler & - & - & 29 & 148 & 350 & 9873 & 8734 & 8101 \\
\hline \multirow{3}{*}{ Granite } & 0.5 & 0.51 & 61 & 234 & 569 & 9114 & 7784 & 6076 \\
\hline & 1 & 1.27 & 116 & 423 & 1045 & 8734 & 6076 & 3038 \\
\hline & $1.25^{*}$ & 1.82 & 174 & 565 & 1607 & 8354 & 4937 & 1898 \\
\hline \multirow{3}{*}{ Limestone } & 0.5 & 0.42 & 55 & 187 & 541 & 9492 & 8355 & 6582 \\
\hline & 1 & 1 & 83 & 325 & 871 & 9114 & 7595 & 5696 \\
\hline & 1.25 & 1.38 & 123 & 430 & 1103 & 8861 & 6835 & 4937 \\
\hline \multirow{3}{*}{ Lime } & 0.5 & 0.15 & 36 & 146 & 446 & 9492 & 8354 & 6835 \\
\hline & 1 & 0.32 & 59 & 216 & 553 & 8734 & 7595 & 6076 \\
\hline & 1.25 & 0.41 & 68 & 274 & 622 & 8734 & 6835 & 5316 \\
\hline
\end{tabular}

(*): At this granite concentration, the mastic is excessively viscous; therefore, it was prepared at a higher temperature than that used with the other fillers.

The variation in the stiffness modulus and failure strain with the volumetric concentration used with each filler for the three test temperatures is plotted in figures 7 and 8.

Figure 7 shows how the stiffness modulus of all mastics increases with decreasing the temperature and increasing the filler concentration. Granite has the highest stiffness increase with filler concentration, followed by limestone, whereas lime exhibits the 
Consequently, the failure strain decreases with decreasing the temperature and increasing the filler concentration, Figure 8 . At $20^{\circ} \mathrm{C}$ the behaviour of the three fillers is very similar. However, at $10^{\circ} \mathrm{C}$ and $0^{\circ} \mathrm{C}$ granite exhibits the greatest loss of ductility, especially at $\mathrm{Cv} / \mathrm{Cs}$ higher than 0.5 .

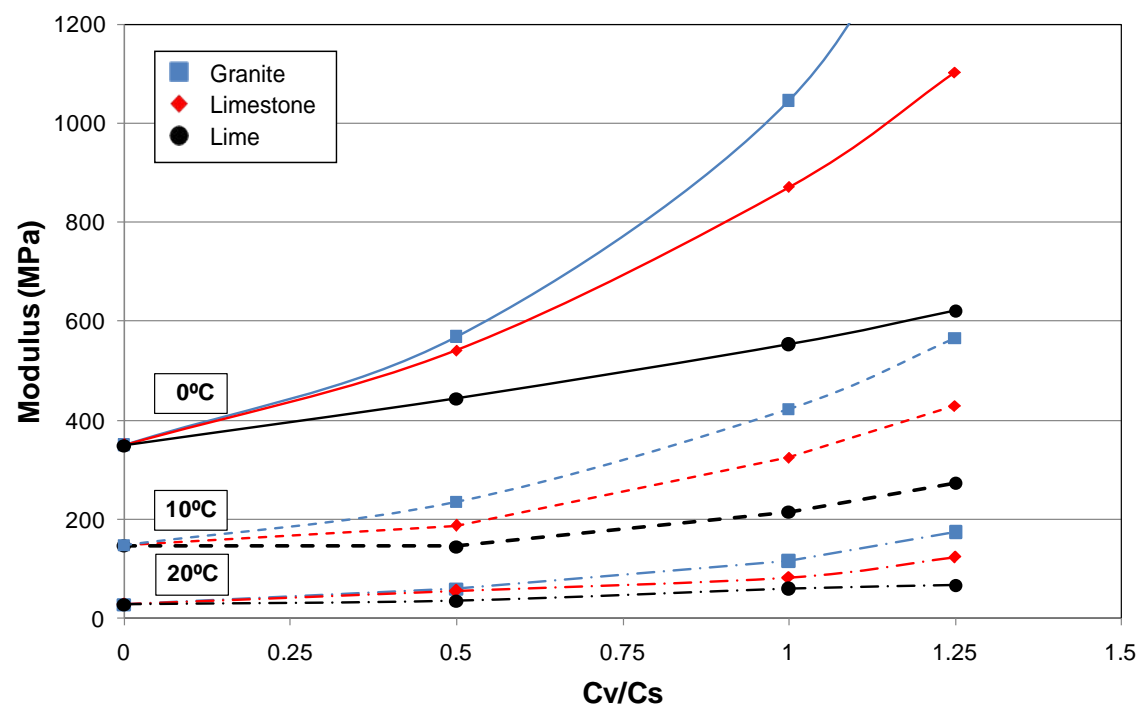

Figure 7. Stiffness modulus versus temperature and volumetric concentration for mastics manufactured with the three fillers

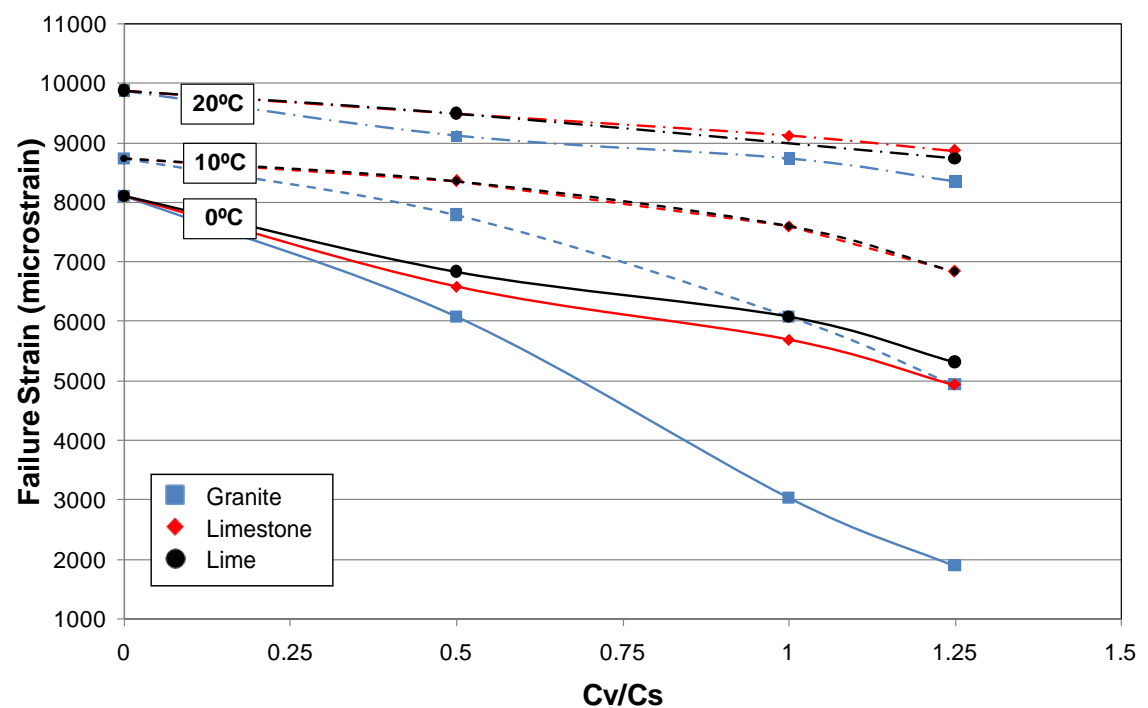

Figure 8. Failure strain versus temperature and volumetric concentration for mastics manufactured with the three fillers

In general, if the volumetric concentration does not exceed the critical concentration, the addition of appropriate filler causes a moderate decrease in failure strain, but also a significant increase in the stiffness modulus. This improves the fatigue response of the mixture.

As was shown in Figure 1, maximum particle size of lime is lower than those of limestone and granite. The effect of this variable on the mastic behaviour could have 
prevented the modulus from increasing, as Ward and McDougal [32] and Kandhal and Parker found [33]. As they stated, not all the fine materials act as a filler; they could act as an extender of bitumen; although this hypothesis should be analysed in greater detail in order to confirm this phenomenon.

337 If the variation of these parameters, i.e. stiffness modulus and failure strain, is represented based on the filler/bitumen ratio by mass, Figures 9 and 10, some differential aspects can be observed. The modulus increases with the mass of filler; the variation for granite and limestone is very similar, in such a way that for the same $\mathrm{f} / \mathrm{b}$ ratio, the stiffness modulus is almost the same for both fillers. In contrast, a rapid stiffening (modulus increase) of the mastic prepared with lime is observed with relatively small amounts of this filler, as Figure 9 shows.

Moreover, the analysis of variation in failure strain with the filler/bitumen ratio by mass shows again the difference in behaviour between lime and the other two fillers since the failure strain decreases rapidly with increasing the mass of lime, Figure 10. Additionally, although the stiffness modulus of the limestone and granite fillers is very similar, now it is observed that the failure strain of granite is much lower than that of limestone.

Extrapolation of the lime curves shows that it would be almost impossible to manufacture mastics with the filler/bitumen ratios by mass specified in Spain (between 0.9 and 1.2 for AC mixtures), and that even at lower ratios the mastic would be very stiff and undergo a brittle fracture, leading to a totally inappropriate behaviour.

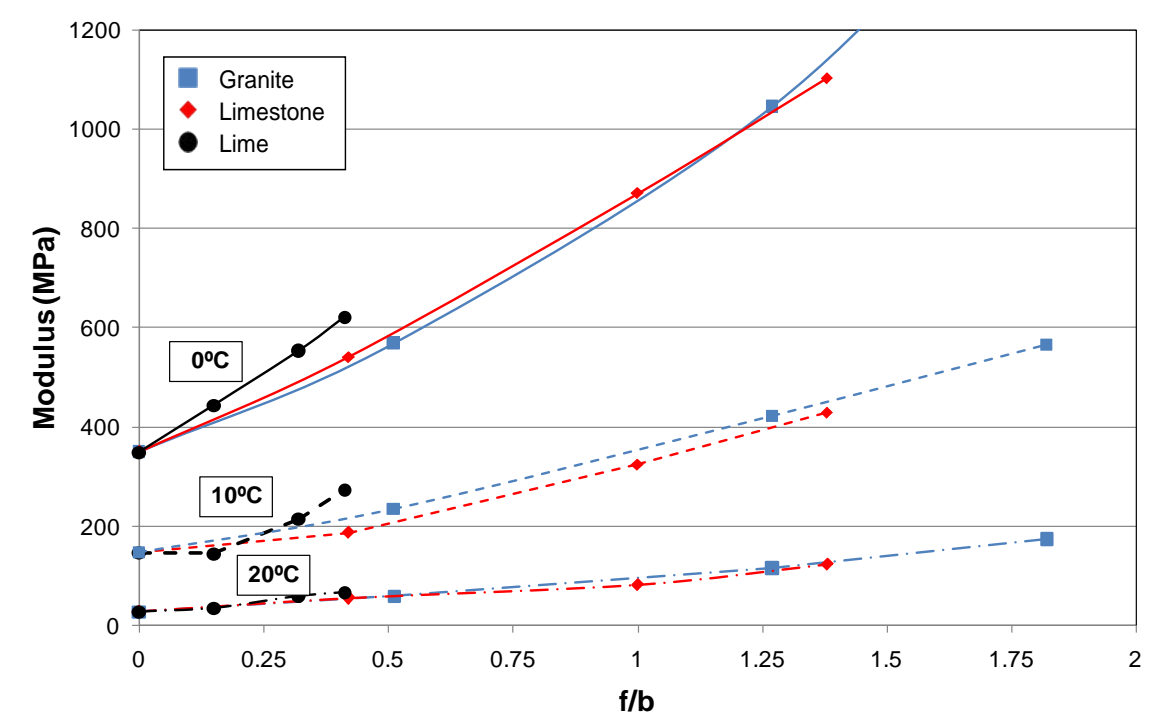

Figure 9. Stiffness modulus versus temperature and filler/bitumen ratio by mass for mastics manufactured with the three fillers 


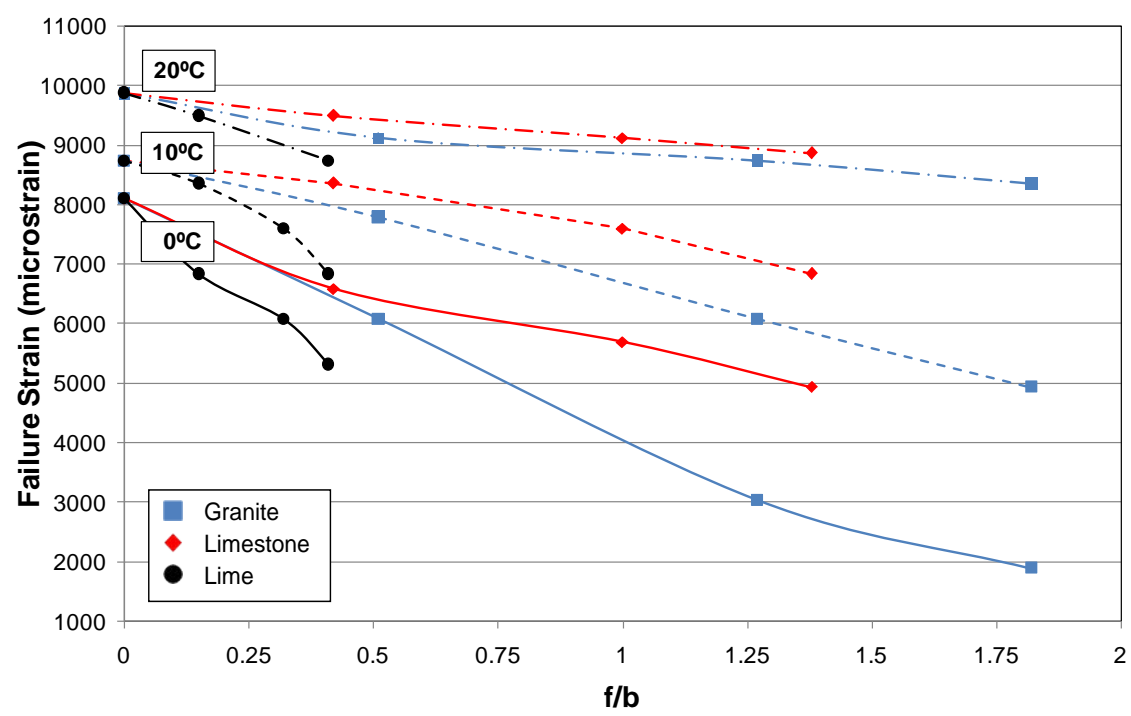

Figure 10. Failure strain versus temperature and filler/bitumen ratio by mass for mastics manufactured with the three fillers

Finally, Figures 11a, 11b and 11c show the relationship between stiffness modulus and failure strain and the neat bitumen curve for each concentration of filler at all test temperatures. Comparison of these figures reveals clear differences in the behaviour of the mastics.

370

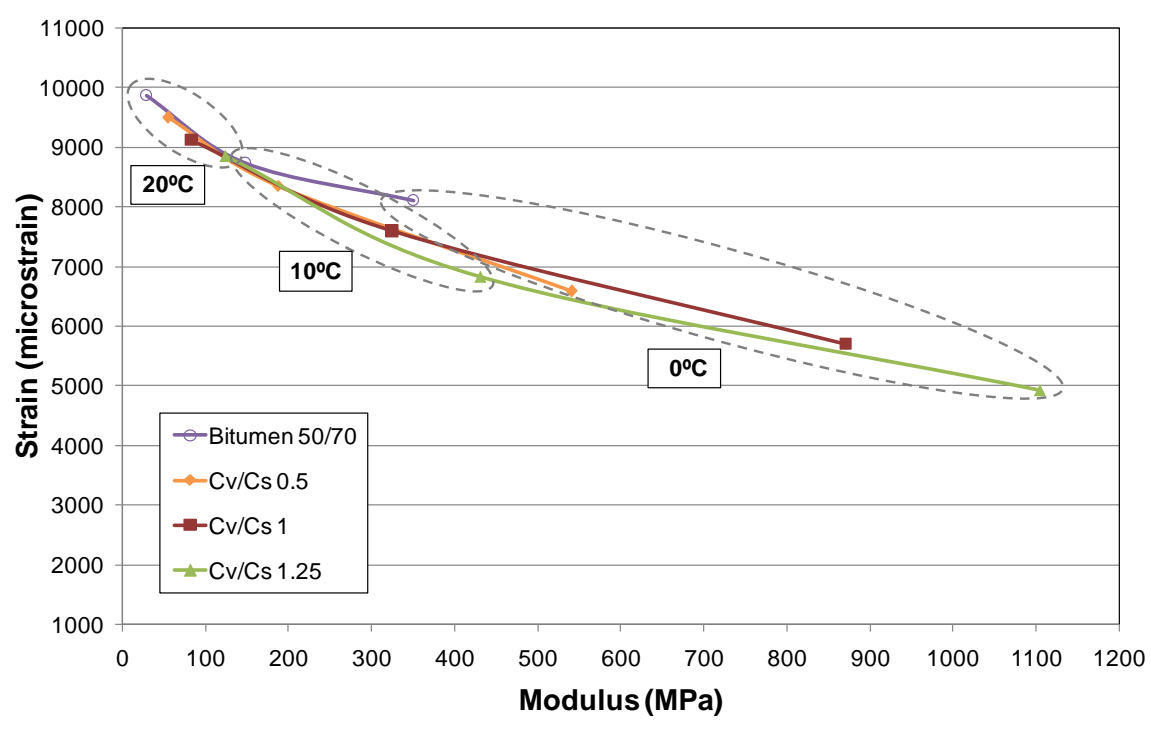

(a) 


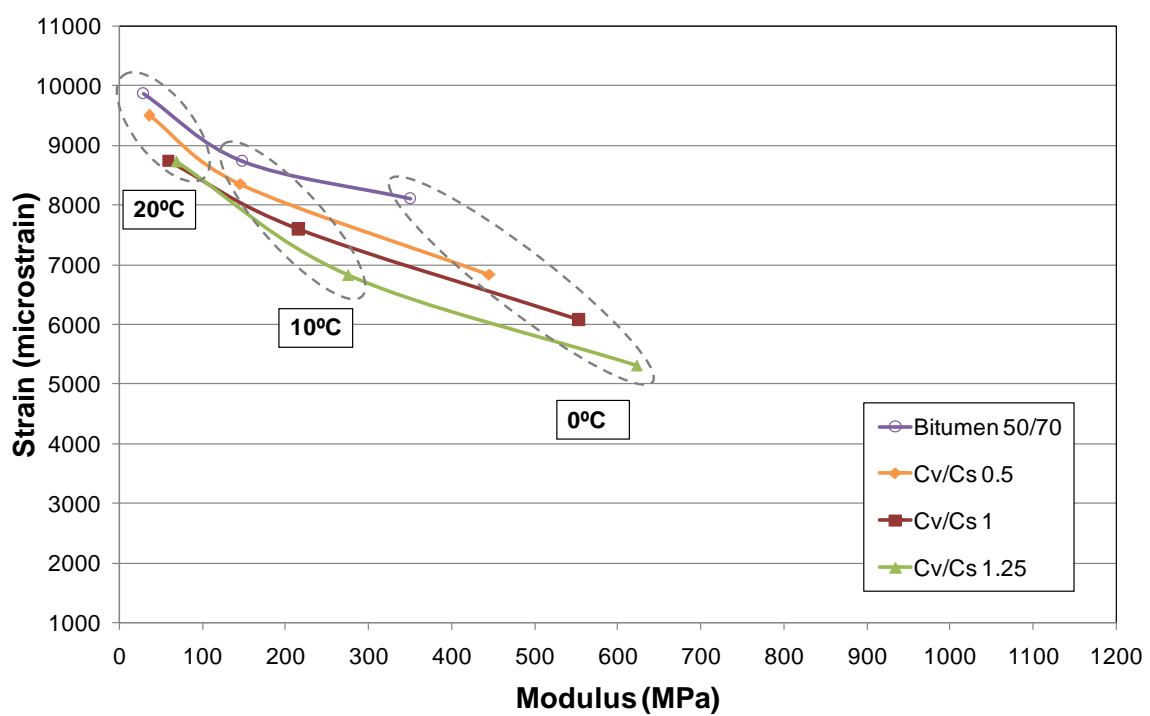

(b)

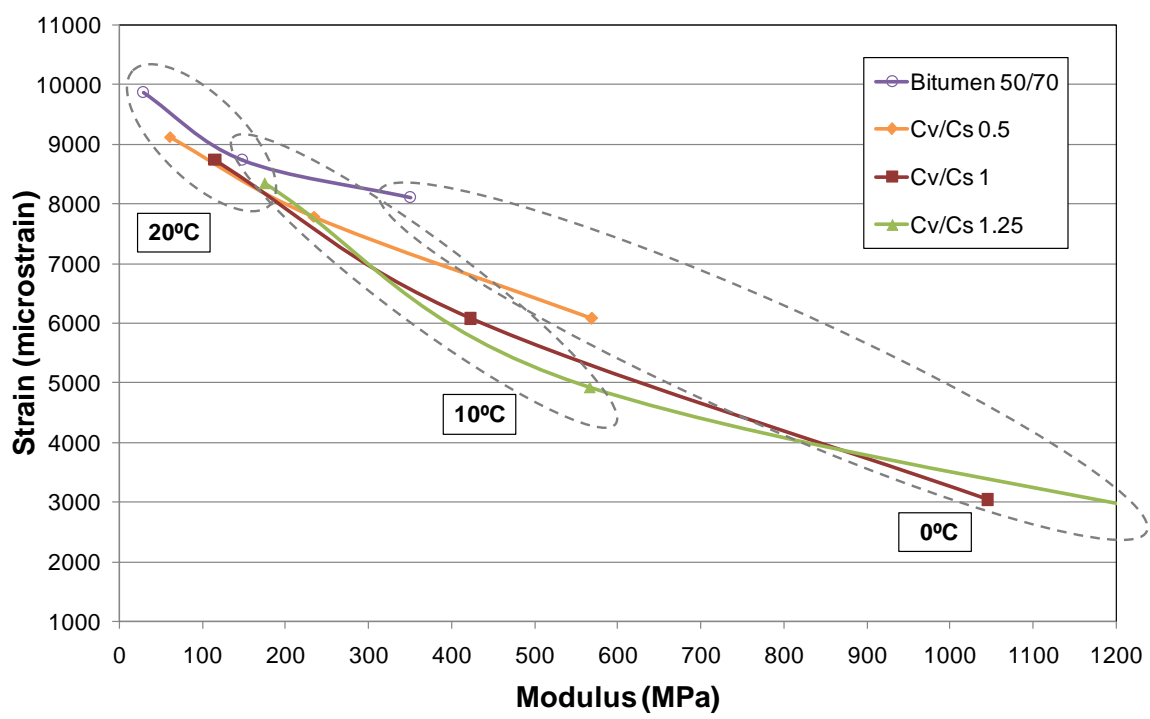

(c)

Figure 11. Failure strain versus modulus at $20^{\circ} \mathrm{C}, 10^{\circ} \mathrm{C}$ and $0^{\circ} \mathrm{C}$ and different volumetric concentrations for the mastics manufactured with: (a) limestone, (b) lime and (c) granite

For the limestone filler, Figure 11a, the curves obtained at different temperatures and concentrations tend to overlap. The stiffness variation produced when increasing the filler content in the mastic shows a similar slope as that produced by the temperature decrease, although this does not mean that the variations are equivalent.

In the case of the lime filler, Figure 11b, the curves for each concentration tend to separate, remaining more or less parallel to each other. If points of equal temperature (surrounded by dashed ellipses) are joined, the slope of the resulting curves would be very different from the slope of the curves of equal filler content (equal $\mathrm{Cv} / \mathrm{Cs}$ ). So, the variation of failure strain and modulus is very different considering the temperature effect than considering the filler content effect. And in the case of granite, Figure 11c, 
minor changes in behaviour are observed with increasing concentration at $20^{\circ} \mathrm{C}$, whereas at low temperatures $\left(0^{\circ} \mathrm{C}\right)$ the filler behaves significantly differently, showing a sharp increase in stiffness and fragility with increasing filler content.

Figure 12 shows the curves corresponding to the concentrations of the three fillers at the same test temperature, i.e. $0^{\circ} \mathrm{C}$. All the curves tend to converge at the point representing the neat bitumen with decreasing volumetric concentration of filler in the mastic. Furthermore, the decrease in failure strain with increasing stiffness modulus is more pronounced for the lime and granite fillers. The latter performs worse since, at a given concentration of filler, the decrease in strain and increase in modulus are much more significant. The limestone filler has the best performance since the slope of the modulus-strain curve is smaller; that is, for the same increase in modulus the failure strain remains high.

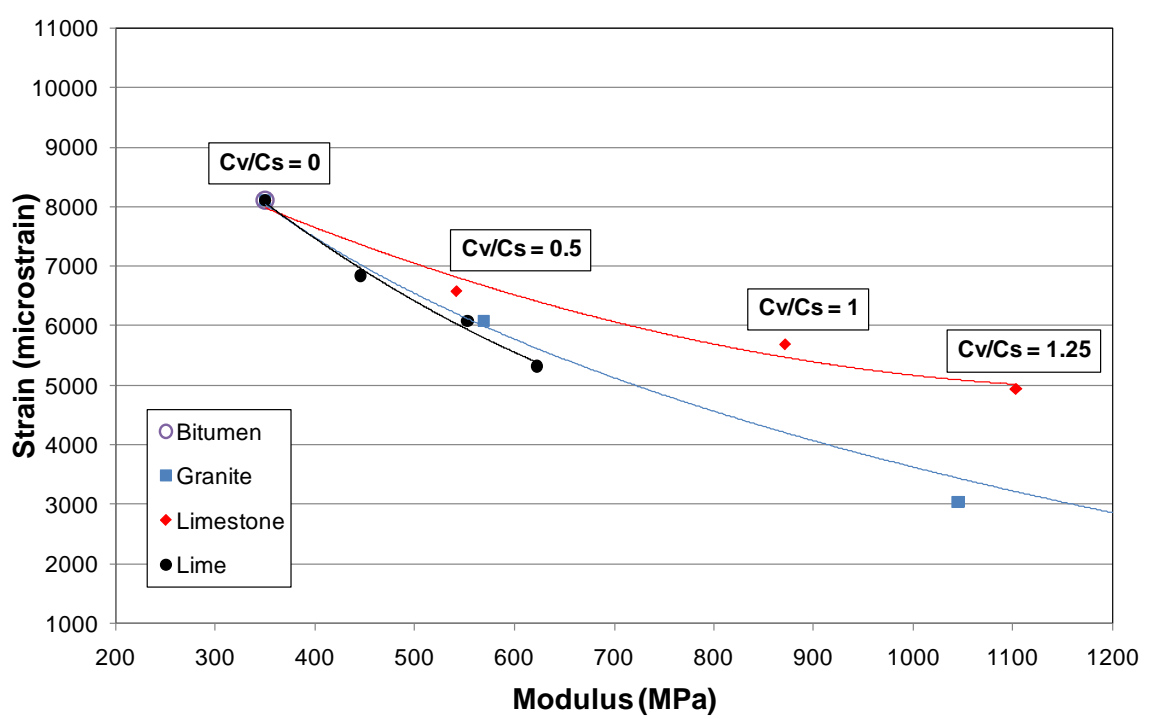

Figure 12. Failure strain versus modulus at different volumetric concentrations at $0^{\circ} \mathrm{C}$ for the bitumen and the mastics manufactured with the three fillers.

\section{Conclusions}

This study investigates the effect of filler type and content on the fatigue behaviour of mastic at different temperatures $\left(20,10\right.$ and $\left.0^{\circ} \mathrm{C}\right)$ by EBADE test. Three different mastics prepared with conventional 50/70 penetration grade bitumen and three types of fillers (two natural types, a granite and a limestone filler, and a hydrated lime) were analysed at different volumetric concentrations.

The following conclusions can be drawn from the obtained results:

- An increase in the volumetric concentration of filler in the mastic results in increased stiffness modulus and decreased failure strain, especially at lower temperatures, with the granite filler showing the highest variations. Granite has an average particle size and a clearly different particle shape.

- For the same volume ratios $\mathrm{Cv} / \mathrm{Cs}$, the limestone and lime fillers have similar ductility at all test temperatures. However, considering their mass proportions, a smaller amount 
of lime than limestone or granite must be used as the increase in stiffness modulus and decrease in strain occur at a much lower filler/bitumen ratio by mass.

- The modulus-strain curve of the limestone filler has the smallest slope, meaning that this filler has the best fatigue behaviour. That is, the failure strain of limestone remains high for the same increase in stiffness. Granite stiffens the mastic excessively, and a content increase results in a significantly lower failure strain, especially at low temperatures; reason why it could be recommendable to limit the amount of granite to be used in the mixture. On the other hand, lime has the lowest stiffness modulus despite exhibiting a high failure strain.

\section{Acknowledgements}

The authors would like to thank the Ministerio de Economía y Competitividad for its assistance in the project PROFIS (BIA2012- 36508), established within the framework of the VI Plan Nacional de Investigación Científica, Desarrollo e Innovación Tecnológica. The authors would also like to acknowledge the company REPSOL for supplying and characterizing the bitumen used in this study, and UPC researchers Marilda Barra and Diego Aponte for their help in conducting the optical microscopy tests.

\section{References}

[1] Tunnicliff, D.G. (1961). A Review of Mineral Filler. Journal of the Association of Asphalt Paving Technologists, Vol. 31, pp.119-147.

[2] Harris, B.M. \& Stuart, K.D. (1995). Analysis of Mineral Fillers and Mastics Used in Stone Matrix Asphalt. Journal of the Association of Asphalt Paving Technologists, Vol. 64, pp.54-95.

[3] Heukelom, W. \& Wijga, P.W.O. (1971). Viscosity of Dispersions as Governed by Concentration and Rate of Shear. Journal of the Association of Asphalt Paving Technologists, Vol. 40, pp. 418-437.

[4] Tayebali, A.A., Malpass, G.A. \& Khosla, N.P.. (1998). Effect of Mineral Filler Type and Amount on Design and Performance of Asphalt Concrete Mixtures. Journal of the Transportation Research Record, No. 1609, Transportation Research Board of the National Academies, Washington, D.C., pp. 36-43.

[5] Wang, H., Al-Qadi, I.L.; Faheem, A.F., Bahia, H.U., Yang, S. \& Reinke, G.H. (2011). Effect of Mineral Filler Characteristics on Asphalt Mastic and Mixture Rutting Potential. Journal of the Transportation Research Record, No. 2208, Transportation Research Board of the National Academies, Washington, D.C., pp. 33-39.

[6] Pérez-Jiménez, F., Barral, M., Soto, J.A. \& Navarro, J.A. (2008). Effect of the Nature and Filler Content on Cohesion, Adhesiveness and Rheological Behaviour of the Bituminous Mastics. Eurasphalt\&Eurobitume Congress, Copenhagen, 2113 May 2008. 
[7] Pérez-Jiménez, F., Miró, R. \& Martínez, A. (2008). Effect of Filler Nature and Content on the Behaviour of Bituminous Mastics. Road Materials and Pavement Design, Vol. 9, pp. 417-431.

[8] Faheem, A., Hintz, C., Bahia, H. \& Al-Qadi, I. (2012). Influence of Filler Fractional Voids on Mastic and Mixture Performance. Journal of the Transportation Research Record, No. 2294, Transportation Research Board of the National Academies, Washington, D.C., pp. 74-80.

[9] Delaporte, B., Di Benedetto, H., Chaverot, P. \& Gauthier, G. (2008). Effect of Ultrafine Particles on Linear Viscoelastic Properties of Mastics and Asphalt Concretes. Journal of the Transportation Research Record, No 2051, Transportation Research Board of the National Academies, Washington, D.C., pp. 41-48.

[10] Delaporte, B., Di Benedetto, H., Chaverot, P. \& Gauthier, G. (2009). Linear Viscoelastic Properties of Bituminous Materials Including New Products Made with Ultrafine Particles. Road Materials and Pavement Design, Vol. 10, No. 1, pp. 7-38.

[11] Clopotel, C., Velasquez, R. \& Bahia, H. (2012). Measuring Physico-chemical Interaction in Mastics using Glass Transition. Road Materials and Pavement Design, Vol. 13, No. S1, pp. 304-320.

[12] Hesami, E., Jelagin, D., Kringos, N. \& Birgisson, B. (2012). An Empirical Framework for Determining Asphalt Mastic Viscosity as a function of Mineral Filler Concentration. Construction and Building Materials, Vol. 35, pp. 23-29.

[13] Hesami, E., Birgisson, B. \& Kringos, N. (2014). A new protocol for measuring bituminous mastic viscosity as a function of its filler concentration. Road Materials and Pavement Design, Vol. 15, No. 2, pp. 420-433.

[14] Ridgen, P. (1947). The use of Fillers in Bituminous Road Surfacing - A study of filler-binder system in relation to filler characteristics. Journal of Society of Chemical Industry, No. 66, pp. 9-299.

[15] Ruiz, C. (1947). Sobre las Propiedades Mecánicas del Sistema Fíller-betún. Proceedings Segunda Reunión Anual del Asfalto, Buenos Aires, Argentina, November 17-22, pp. 25-52 (in Spanish).

[16] Ruiz, C. (1960). Concentración Crítica de Filler, su Origen y Significado en la Dosificación de Mezclas Abiertas. Dirección de Vialidad de la Provincia de Buenos Aires, Argentina, Publicación Nº11.

[17] Buttlar, W.G., Bozkurt, D., Al-Khateeb, G.G. \& Waldhoff, A.S. (1999). Understanding Asphalt Mastic Behavior through Micromechanics. Journal of the Transportation Research Record, No. 1681, pp. 157-169. 
[18] National Cooperative Highway Research Program NCHRP Report XXX for Project 9-45. Test Methods and Specification Criteria for Mineral Filler used in HMA Revised Draft Final Report 12/28/2010 from University of WisconsinMadison.

[19] Faheem, A., \& Bahia, H. (2011). Modelling of asphalt mastic in terms of fillerbitumen interaction. Road Materials and Pavement Design, Vol. 11, Sup 1, pp. 281-303.

[20] Shen, S., Airey, G., \& Carpenter, S. (2006) A Dissipated Energy Approach to Fatigue Evaluation. Road Materials and Pavement Design, Vol. 7, No. 1, pp. 4769.

[21] Yin, H., Buttlar, W., Paulino, G., \& Di Benedetto, H. (2008) Assessment of Existing Micro-mechanical Models for Asphalt Mastics Considering Viscoelastic Effects. Road Materials and Pavement Design, Vol. 9, No. 1, pp. 31-57.

[22] Botella, R., Pérez Jiménez, F. \& Miró, R. (2012). Application of a Strain Sweep Test to Assess Fatigue Behavior of Asphalt Binders. Construction and Building Materials, Vol. 36, pp.906-912.

[23] Ahmadinia, E., Zargar, M., Karim, M.R., Abdelaziz, M. \& Shafigh, P. (2012) Using waste plastic bottles as additive for stone mastic asphalt. Materials and Design, Vol. 32, pp. 4844-4849.

[24] IRAM Standard No. 1542 (1983). Material de relleno "filler" para mezclas asfálticas. Método de determinación de la relación crítica (concentración crítica) y de la densidad. Instituto Argentino de Normalización y Certificación, Argentina.

[25] Bressi, S., Dumont, A. \& Partl, M (2016). An Advanced methodology for the mix design optimization of hot mix asphalt. Materials and Design, Vol. 98, pp. 174185.

[26] Antunes, P., Ramalho, A. \& Carrillo, E. (2014) Mechanical and wear behaviours of nano and microfilled polymeric composite: effect of filler fraction and size. Materials and Design, Vol. 61, pp. 50-60.

[27] Antunes, V., Freire, A., Quaresma, L. \& Micaelo, R. (2015) Influence of the geometrical and physical properties of filler in the filler-bitumen interaction. Construction and Building Materials, Vol. 76, pp. 322-329.

[28] Antunes, V., Freire, A., Quaresma, L. \& Micaelo, R. (2016) Effect of the chemical composition of fillers in the filler-bitumen interaction. Construction and Building Materials, Vol. 104, pp. 85-91.

[29] Movilla-Quesada, D., Raposeiras, A., Castro-Fresno, D. \& Peña-Mansilla, D. (2015). Experimental study on stiffness development of asphalt mixtures containing cement and $\mathrm{Ca}(\mathrm{OH})_{2}$ as contribution filler. Materials and Design, Vol. 75, pp. 157-163. 
[30] Mo, L., Huurman, M., Wu, S., \& Molenaar, A. (2009). Ravelling investigation of porous asphalt concrete based on fatigue characteristics of bitumen-stone adhesion and mortar. Materials and Design, Vol. 30, pp. 170-179.

[31] Miró, R., Martínez, A. H., Moreno-Navarro, F., \& del Carmen Rubio-Gámez, M. (2015). Effect of ageing and temperature on the fatigue behaviour of bitumens. Materials \& Design, 86, 129-137.

[32] Ward, R. E., \& McDougal, J. M. (1979). Bituminous concrete plant dust collection system--effects of using recovered dust in paving mix (No. FHWA/WV79-003 Final Rpt.).

[33] Kandhal, P. S., \& Parker, F. (1998). Aggregate tests related to asphalt concrete performance in pavements (No. 405). Transportation Research Board. 